ACtive, Programmable, AND

MOBILE CODE NETWORKING

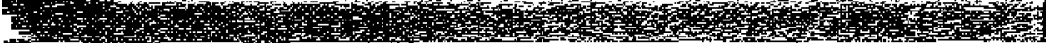

\title{
Composing Protocol Frameworks for Active Wireless Networks
}

\author{
Amit Kulkarni and Gary Minden, University of Kansas
}

\begin{abstract}
This article describes a new mendel for it compesible protocol francwork litat is suitable for the rapid development of any apjolication-specilic serviee and its deployment in the netwatk. The class-hierarcly model described here enables users to compose their awn eustom, flexil) frameworks from either predefined ar custom protocol components tailored to an application's needs. Wo validate experimentally that application-spucific frameworks inplementing custom prolocols can be developed to improve petrormance of applicalions over wircless nelworks.
\end{abstract}

\section{INTRODUCTION}

Recently we have seen a proliferation of wireless devices that connect lo the Jnlertict and offer inylime/anywhere [nternet alcess. [lowever, there is a dichotomy between the clatracteristics of wirclest moibile nelworks and the wired infinstructure. The primary chatracteristics of wircless molvile networks are relatively lower hanowidith, intermittent conncetivity, and higher orm rates. Wired neworks offer high bandwith, steakly connectivity, and wery low crror rates. J3andwidt $t_{1-}$ intensive or near-real-time applicitions roquire special harkfing to surmount the limitations of witeless mobile networks and the itoterconncetion of wircless and wircil nelworks to provicle sat isfiactory pertorminee to the aser. In most eases, new and custum protocols are developed and deployed in lle wireless network to meet user necds. Unforlunately, the current network inftastructure is rigitl, and the protoed slack in the network is usually lixed. Doveloping and introdueing new protucoss in the network requires a time-consuming standindization process.

Active nelworking [l] provides a new paradigm ia which tloe nodes of tle network are programmaly (i.e., they provide an execution plation on which user colle cat be executed). Ache nodes are programmable elenents in an active notwork that enable the deploynent of custom services and protocols, Smatrackets are cxecutable entities hiat ate the basic means of communication in an active network. Smartlackcts are characterized by a unique type and, optionally, a destination address, dibtib, and progratrin code in the form of methods that wat be exeeuted Joeally it any ande in the active net- work. Applicalions customize network resources for dymamic adijutation by itjoctitg SmattPackuls into the active network to inndify behavior of the iletive liodes.

Smatt tackets can potentially eary code in the form of application-specific protocol fiameworks composed from custom protoeols. This atses scweral interesting questions:

- What kind of framework is required to rapidly ereate application-specific protocol linmeworks?

- What services cuu be identified and developed that can benefit traditional applications runing over wireless networks?

In this article we alescribe a llew model for a protocol frantework that is stritable for rajuid ilevelopunent of any application-specitie service and its deployment in the network. The classhierarchy inodel described here enables users to compose their own cuslom, flexible frameworks from either preslefined or custom protocol components tailored to an appication's needs.

The arlicle is organized ats follows. In the next section we deseribe the limitations of the tracitional layered network model and cxplain why it is unsuitable for active networking. Wo investigate proper ties thet customizable protocol francworks muse possess to be usetul for actiwo networking. Wo describe the class-hiertrehy model llat satis[ics these properties and enath]es us to create custonizable protocol framewotks. We also deseribe an active nelworking prototype called Magician that uses the class-hierarchy model to enable uscrs to entrpese applieationspecite frameworks. We describe two active networking services that were created in Magician for applications t'ansmittitig neal-real-lime data over wireless links. $\Delta$ discussion about the petformance of an application using the eustom protocol stack in all active network vis-a-vis using traditional nelwork infrastrueture is also incleded. Finally, wo describe pelated resentch it this atea before concluding with a summary.

\section{BACKGROUND}

I'rnditional networking protocols werc built for largely non-real-cime data with very few burst requirements. The protocol slack at a network node is fixed, and the network notes only manipulate protocols up to the network layer. Now protocols such as Real-Time 'l'ransler l'rotocol 
(RTP) and I lypertext 'T'ransfey l'rotocol (I'I'T'P') enalole the nefwork to tratsport other lypes of application data such as real-time and multimedia dalin. Such protocols cater to specific dernamels of the application data. But transporting those new dala lypes ower a legacy network requijes us to tratsiom the new type of data into the type of data carricd by the network. Transtoming the data to lit legacy protocol requirements prevents one from unclerstanding the transformed protoool. For eximple, embedding an MPtici trame in MIMF, format prevents one from ensily recogaizing anl $I$, $P^{\prime}$, or $B$ ftame. This prevents the network from taking suitable action on the MPLG frame during times of congestion.

Second, introslucing new protocols in the curtent infrastructure is it clifficult and time-consuming process. A committec has to agree on the detinition of a now protocol. 'This involves algreeing on a struclure, states, algorithuns, and funclions lor the protecol. 'The time from coneeptualizat ton of at protocol to its actual deploynent in the network is usually cxtraordirarily long.

Tradilional protocol frameworks use layering as a composilion mechensism. J'rotocols in onc latyer of the slack carmol guarantee the properties of the layers underneatle it. Sach protocot layer is treated like a black box, and there is no mechanism to identify il linctional redumblaneies vecul in the stack. Sometimes protocols fils ditferent layers of the same stack need to shatre inlormation. For example, TCP calculates a checksum over the 'TCP messatge and llie $\mathrm{Il}^{3}$ heater [2]; but in doing so, it violates modularify of the layering model becatese it nects informat fioul liom the [I' header that it gets by directly accessing the Il' header. F'urthemote, laycring hides lunet ionality, which can introduce redurElancy in the protocol stack.

Ais advantage of active networking is that it cnables application-specific processitg througl the dynamic deployment of user-defined protocol slatck at the metwork nodes. These prolowol sitacks are created by composing functionality tailoted to the data type Leing I rankported. 'The clallenge is to identily an :pproach thit emaloses creation of flexible, custom, complete, and correct protocol stacks, which can be then injected into the network.

\section{Properties of Customizable Protocol Frameworks}

Fitrlier reseitch on llexible protocol sticks like I Iorus [3] and the $x$-kernel [4] showed that it is at gond iclea to replatee monolithic protocols with a corrposition of anall protocol thothles, ead implementing it specilie function i.e, the framewark should rapyon contyosilde protocols. A single monolithic 'TC' protocol is replaced by a sulte of components, each of whicls implements various functions of 'C'CP' such as checksumming, sequencing, and flow control. Moclularity wables the cration al complex but flexible application-specife protocol rameworks from predelined, tested compounests I'his streamlines line protocol stack, and applicalions do root heve to deal with seperfluous functionality. Performance measurements on the I Iorts protocol stack have demonstrated that modulatily deses mot necessurily degrade jer bormance [3].
T'he traditional protocol implementation is rigitly iniplemented in the kernet of the operating system of the end system or the control software ol it switch or rouler. Very lintited customization is possible in such implementattions locatuse the protocol framework at the network nodes provides only limited acesss to the implementation state. It is alsu difficult to ehange the beliavior of a protocol installad at a lietwork node to suit the user. 'The user is foreed to find workanounds to implement the desired functionality. C'his often leads to inmplementation hacks that are often suboptimal and nomreusable. 'T'o promote flexibility, reusilbility, and the creation of ligh-confidence protocol eomponents, it is necessary to grive the user more control ower the creation, custonization, and deployment of protocols. One approade to achicve this is to open up lle protocol implementation and provide the user with enough tools to contmol its belavion.

T'o enlance rensability of protocol components, they should possess ai formal, woll-ilefined interface that abstracts the innes workings, but presents the user with a rich representation of its behavior. This is detined as the property of inmospection. Introspection enables a user to access the implementation state and work with abstractions to the solected implementation state. It the context of actiwe networking, this increases reusubility because prolocol components seltisfying this property can be reused in different protocol tramcworks.

'Tle property of intewession enables a IIser to modify the bebavior of an abstraction. 'L'te user relites existing behavior or iddjusts the implementation strategy to improve performance. This is usually achicved through the mechanism of inheritunce in oljoct modeling, enabling users to customize previously developed active network protocols to tailor them to the needs of the application wilhout Javing to write new protocols fiom seraldi. [u summary, aclive network protocols must possess the following properties to enable users to build modular, extensible and wetiffalle protoco! [rameworks:

- Modularity - the property of decomposing complex protocols into smaller compronents, chch implementiug a piece of communication functionality

- lutronection - the property of being able In access an existing protocol componetit and work with abstractions to it

- Interecssion - the property of being able to modity behavior of an cxisting protocol componcent

\section{Protocol Composition IN MAGICIAN}

Magician [5] is a toolkit that provides a framework [or erealing Smatliackels ats well as an cuviroment fot executing the Suarlackets. Magician is inplemented in Java. Jaya wats chosen beciuse it supports mobile code, serializillion, and object-oriented [roperties such as inheritance and concapsulation. In Magician, the executing entity is a Java object whose state has to be preserved as il traverses the aelive network. Serialization preserves the state of an
An advantage of active networking

is that it enables

application-specif

ic processing

through the

dynamic

deployment of

user-defined

protocol stacks

at the

network nodes. 


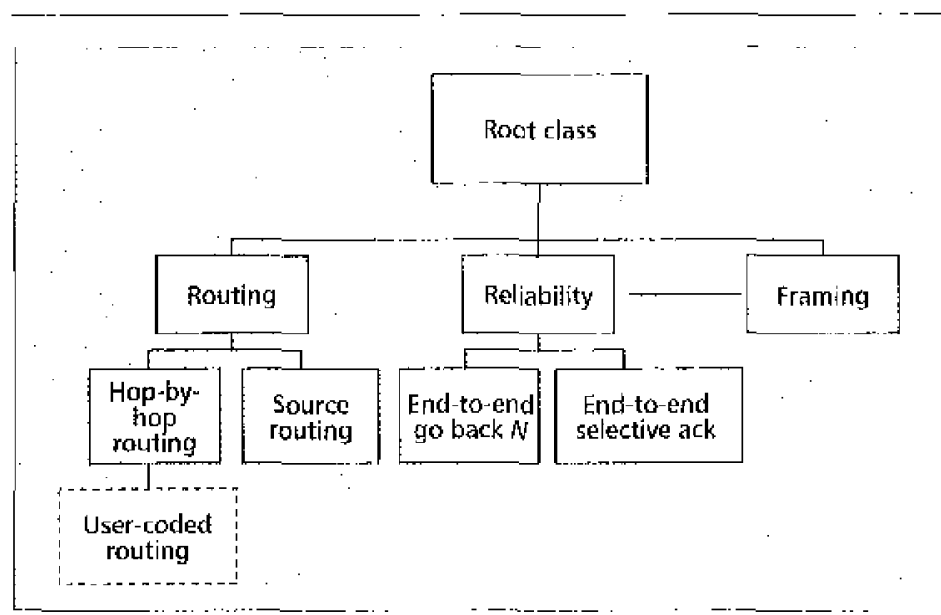

Figure 1. The class hiom my model of an active node.

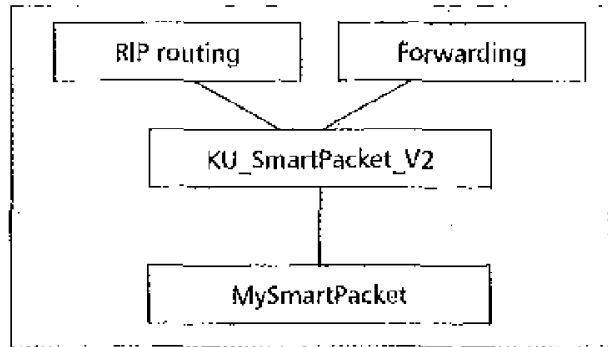

Figure 2. The composition of a bessic turcliable service.

object so llat it enn be transported or saved, and recreated at a later time.

Magician provides a motel in which an active node is represented us a class tuierarclsy, is shown in Fig. L. livery protocol is derived from an alsstract base protocol. Every atetive note provides some basic functionality in the forno of certain default protocols (c.g., routing). Isers may prefer to utilize these default frolocols it they do aot wish to implement their own schemes. 'L'o foster privacy and safety, a unique state is ercalted for each iovocation of the protoces. State that is common to all invocations of a probocol is inviolable and accessible only to users llat lave appropriate aluthorization. Providing each user with a protected copy of the state enables the user lo customize his/ber own state if necessary.

Second, users are permited to instill their own protocols. I[ mecessary, a user creates a new protocol from seratch by extending the base abstract probecol. When the protoeol is carried over to the aclive node by a Smartlacket, a new branch is created for that protocol. Altertatively, the user extends an existing protocol class at the active node and eustomizes it to implement appliention-specific belatvior, as sliown by the exatryple of a user-defined routing algorilhm it Fig, 1, Thus, he is able to inherit certiain basic properties of the parent protocol and provide minor or major behavional modiftentions to tailor it to his application's requirements. In this model, the active node acts as an object whose behavior can be modified dynamically.

The class-hicrurchy nudel for nctive nodes is advantagcous in miny respects. 1t provides the user with llie alsility to customize default functionality at the active nodes using the crtension-by-

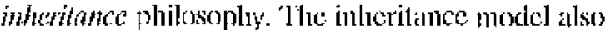
provistes default functionality lor user Smartrackets that choose nof to implement theit own. T'his cmalsles the active node to suppot't transport of passive packets. The unicue state space provided to each invocation of a prolucol curresponds to the instantiation of an objeet from its class definjtion. 'l'his aflotds privacy and safely to the Simartl'acket exeenting in thint. state. It also provides an isolated, secure euvirumment for the exceution of user code sis that the active node can monitor and regulate its activilies. The class model apjoroach differs from the data llow composition model 16], wheren proloco. functionality is activaled only by data flow. Iu the class model, instcal of data being transferred between protocol components, execution control is transferred belween the protocol components. Protocol compunents linve access to the user data and can choose to act on the data or perform other activities.

The cliss model also exhibils the three properlies listed earlier: mudularity, introspection, ind intercession. Modularty is achicved by breaking down conmunication functionality into distiuct protocol components. The functinality of each component is delined in a separate Javi cjass. T'he preperty of interospection is satisfical when protocol components are designed as suitable alstractions and specified witl well-defined interfaces that promote teuse. Using the principles of inheritance and iggregation, these components are composed together to implement the functionality desited of a serviec to be injected in the nelwork. This satisfies the it:leicession properly.

Magician provides two basic predefined frameworks to users:

- A framework prowiding uorelialbe service - $A$ frameswork providing reliable service The fumelionality ut these frameworks is similar to the UIOP' datagram and 'ICP' socket abstrac tious in current networks. Ln Magician, a userdefined SmartPackel utilizing an unreliable delivery serviee is created by extending the KU JSSmatl'acket_V2 class:

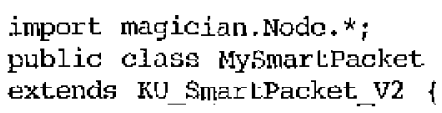

The basic unteliable service, whose composition is slown in Fig. 2, provides forwarding and routing lunctions, The RIP routing protocol is llo default routing protocol implemented by all aclive nodes. T'le $\Lambda L^{\prime}$ L for accessing note resources (getting node name, finding out the next hop, ete.) is provided by the $K \mathbb{L}$ Sniart. Packet V2 interface. On the other hand, user Simartlackets requiring assured delivery service extend the Reliablecomm ['W class:

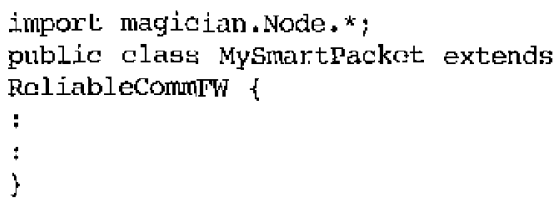




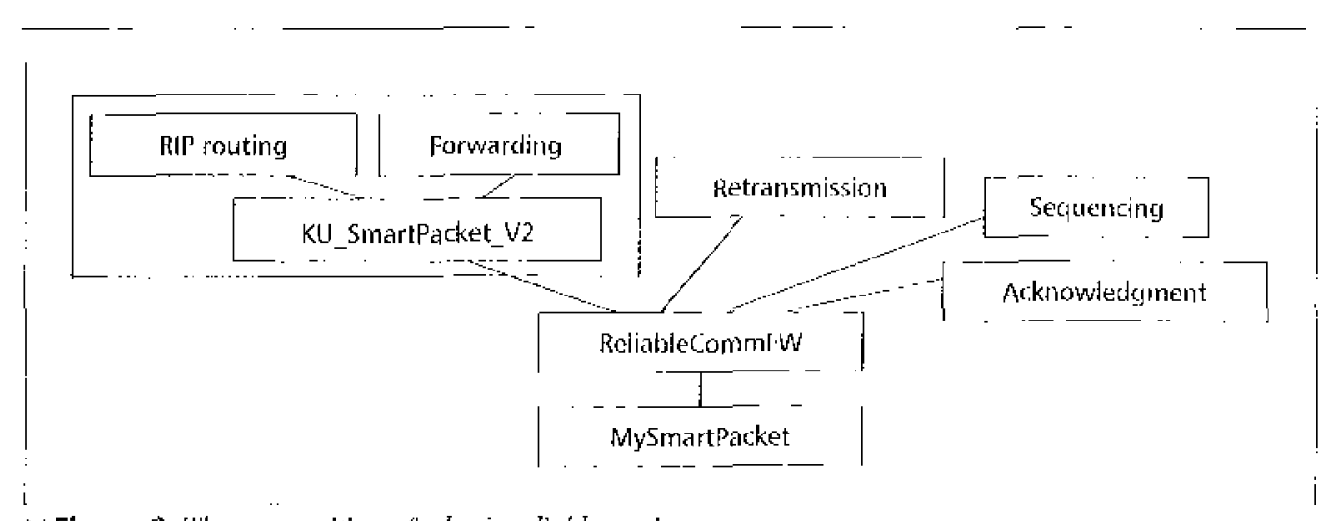

ti Figure 3 . The composition of a busic whale sermice.

The basic reliable service framewerk, slowll in lig. 3, adds is sequencing moclule, a lop-bylop stop-atdd-wait-acknowledgnent protocol component, and a retrallsmission component to provide assured clelivery. $A$ hop-loy-hep protocol is clasen because, in an acliwe actworking enyironuent, the destination ol a SmarlPacket cin ehunge during its exeention all all active node. This is the simpiest reliable delivery mechanism llat ean handle dynaunic destination changes. lor sxample, if al client repuest packet triver'sing the network towird is server note cneounters information about the location of a proxy that merges eluphicate tequests to the server, the request pickel resets its destination to the bocaltion of the proxy. If the packs eontains at reguest that has been inade previnusly, il informas the proxy of the elient's recpuest and destroys itsel". If an end-to-end acknow/celgment/retransmission protocol bis used in this casc, it is bound to fail becaluse the server node never receives the packet and therelore watis.s for the sender to sctrl the packet besillse it is next in septence.

In Magician, users are mol cumstrained to using only lac basic trameworks. Custombation of the liancwork is possible in mirly ways. Users can replace a particula functionality by replacing the protocol module implembinting it. Cunsicler the example of an aclive applieation requiring a cuslom routing alyoril hm. Active noiles in Magician implement the LS I' rouling frutocol as the default, but the robting mantiger at the active node provieles at regist ation fonture to install custem routing protocols. $A$ custom routing protocol is installed for and application type by registering it with the ronting manager at the active rocle. Once registered, all Sinart'ackets bolonging to the applicalion (and shating the stame type) are routed using the chstom louting algorithm. This sxemplitios customization by replacement.

Users can also exicnd lunctionality of a protocol module. For example, all active nodes atre addressed using the naning schenc implemented by the administrator. IIowever, a user can choose to inplentent lis own ndeftessing scheme. A castom adelressing protocol en exlend the default addressing interlace and implement a Lable that maps conligured active mode addiesses into user-supplied adilresses. I'lis enables transparent transiation of addresses while adhuring to the busic nucte $A P$.

\section{APPLiCATIONS FOR WIRELESS NETWORKS}

Wireless elements in an retwork present the peoblems of intermiltent connectivity, law banclwidth, bigh s lebly, and high bit error rates. I ligh

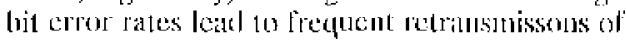
data to ensure reliable delivery lo 1 he applicat tion. This in lun contrihutes lo lower response times in 1he case al real-time ar neall-real-time applications like videoconferencing. Sud applicatons atre delay-sensitive as well as batudwdthintensive, two propetios incompatible with the low-handwidth, higla-kelay chaticteristics of wircless tinks.

Mosi solulions offered so liar lo ematule atplications to fumelion over wireless links are endto-cond or reactive. Applications respond to prolyloms in the network (e.g. congestion) in one of 1wo ways. Applicalions atcl a the condpoints, for example, by backing wit at the soulde to reduce lond on the nelwertk nutil the congestion is alleviated; w alplications provide lints in the headers packels al leats value to the application. These solulions ate lased on the atolion of the network tryithe lo provite best-etion delivery lo the applicallon. But in the catse of realliane or neati-realline arfic. this best-elford aldivery call be too Iate! Wo argue that such alphlications require proactive so] dive solations ane those that redace llwe load on lle nework by eiller discarding datia that is no longer useluf to the appliation ar reduciug bandwidels demand itsell. In an carlice papes we antlind a classilication of scrvices llat can henelit from active networking [7]. 'l'tere we atgued llial lwe classes of services, fillering and merginge, are particularly suitalye for npplications l'unning? over wiled/wircless netwolks. In this section we discuss Lwo prodocols clerived linal llowe disses that cxemplify the endep of proactive solutionts.

lu the context of lle MACi[C-II project, we developed a tow liltering proteod that utilizes the currest state whe the applicaliom lo matively reduce loat an the witeless links in the netwotk. The new protucol enabos loracy MACilC applications like Itera Vision to talor nelwork resources, especially for clients connected over low-bandwidth liuks. These applicallions alle lerrain visualization chiculs that feteh and display imagery ol terrain elata stored on remote servels. Imige tiles are requested in the form of tile ot jurocols that canble the netwark to drojs
Proactivo

solutions are

those that redice

the load on the

network by cither

discarding deta

that is no tonger

useful to tho

application or

reducing

bandwidth

domand iself. 


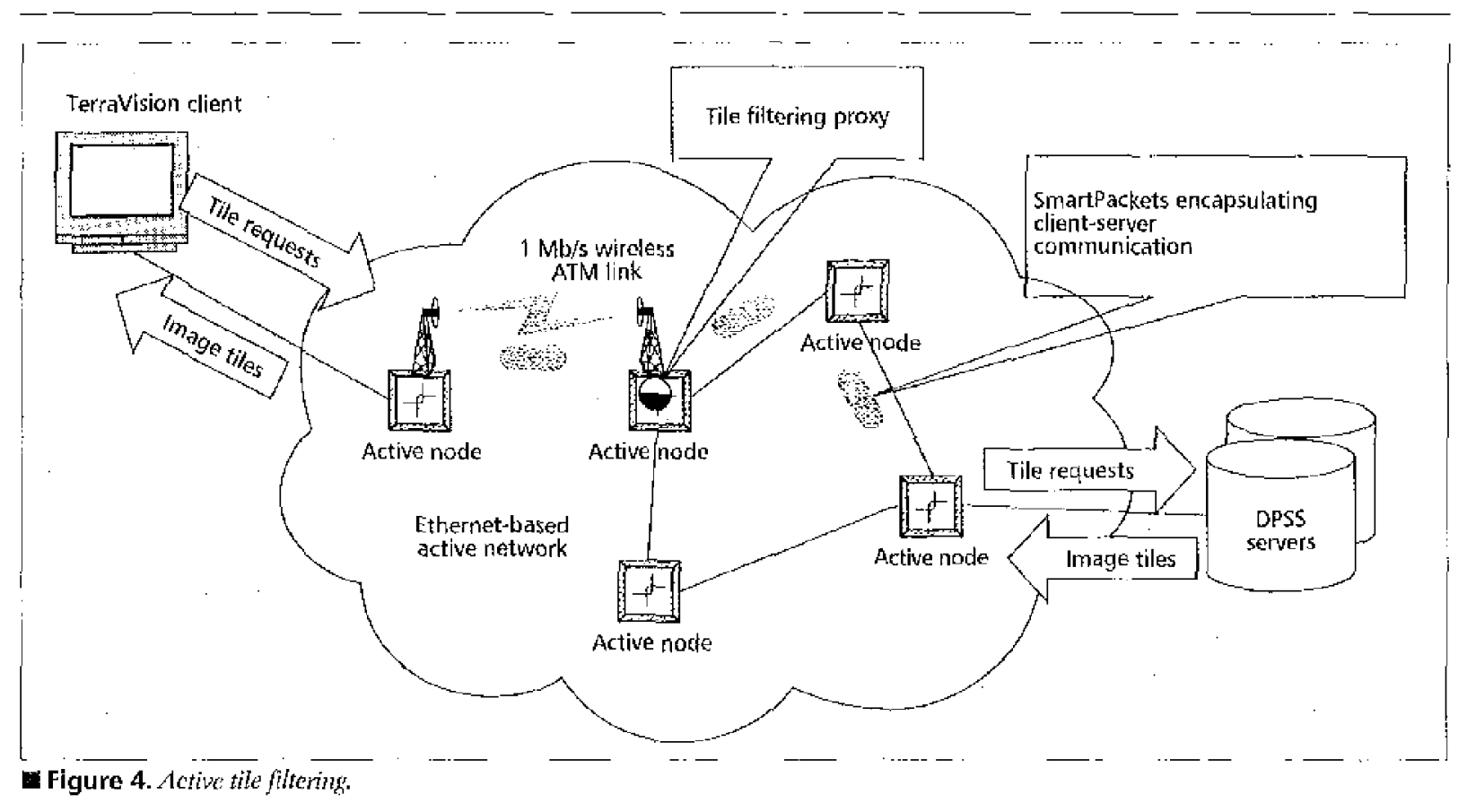

request identifiers that are bundled to form a request frame. 'The requests in each frame conrespond to tiles that are part of the current vicw. The inage data is returned as a set of tiles the client application processes to render the terratin. Wher a user pats the terrain, '[erravisior reguests a large number of tiles. If the user pans the tertain rapidly and there is significant respoose lag, it is cnticely possible that by the time sone of the tiles reach the client, the rame of view has changed, and the tiles are no longer necded and nover displayed.

This scenario oceurs frequently when 'IerraVision runs on a host connected to the network over a wireless liuk. If the user pans very rapidily, the wireless gateway becomes congested, resulting in deteriorated performance. A tratitional I'CP/IP-based network connection attempts to deliver all requested tiles to the client, including those that are eventually dropped. An application-specilic solution to this problem is to prevent taraly iiles (i.e, tiles that are candidates to be dropped by the client) from being transmitted across the wireless link. "ilhis redues the dentand on nctwork resoutecs, which in turn enhanees the ahility of the application to respond to user input because there are nore netwatk resourees available for tiles in the current frame of view.

In active networks, the solution is inplemented in the followitig manner. The client customizes the network by dropping a filtering proxy at the gateway ( 1 ig. 4) which maintains the identifiers of tiles that are currertly requested. Tilcs relutned from the servers that are not part of the eurrent request list tre dropped at the gatcway itsolf. This prevents congestion at the wireless gateway. Since only tiles fron the current request list are allowed to pass ulurough, the user is not limited by the capacily of the wireless link. In etfeet, wo have combated the problem by reducing the demand on the net- work. When the user stops panning, the request list at the gateway does not change as often, cnabling tiles in the current vitw to pass through. 'The application is thus able to quickly synchronire with the user"s demand. 'J'he wireless gateway is identified and set up as a spocial filtering proxy. The existence and locention of the proxy is advettised by sending out beacon packets in an $n$-hop neighborhood of ilie gateway that installs this information in nanied caches at the active nockes. Tile request packets check for this intormalion as they traverse the nework. If existence of the proxy is detcotod, the tile request packets reroute tlemselves to the location of the proxy where the request lrame is deposited.

'The application is crealed by defining scparate SmartPackets that perform the functions of seting up the connection, reguesting the tiles from the server, delivering the requested tiles from the server to the client, locating and seting up the wircless gateway for filtering, and so on. Since we want assuret delivery of smartPackets, all Sinarirackets cxlend the Re1iablecommEw interlace. The default RIP routing protocol is utilized for basic ronting celpabilitics for all packets except boacon packets. Jeacon packets simply multicast themselves on all interiaces of a notle, A maximum hop limit and checks for previous visitation of a beacon packet are used to prevent excossive flooding.

We have also developed a new protocol, called a Request Merging protocol, to reduce butndwidtl demand over wircless links. We trap requests from clients and transparently redired them to nodes on which in proxy cxists that keeps track of the requests made to the server (I Iig. 5), The proxy acts like a beacon and sends information about itself to neighboring nodes periodically in a beacon SmartPacket. The information includes proxy location, tinc sent, expiration time, and number of hops to the proxy. This 


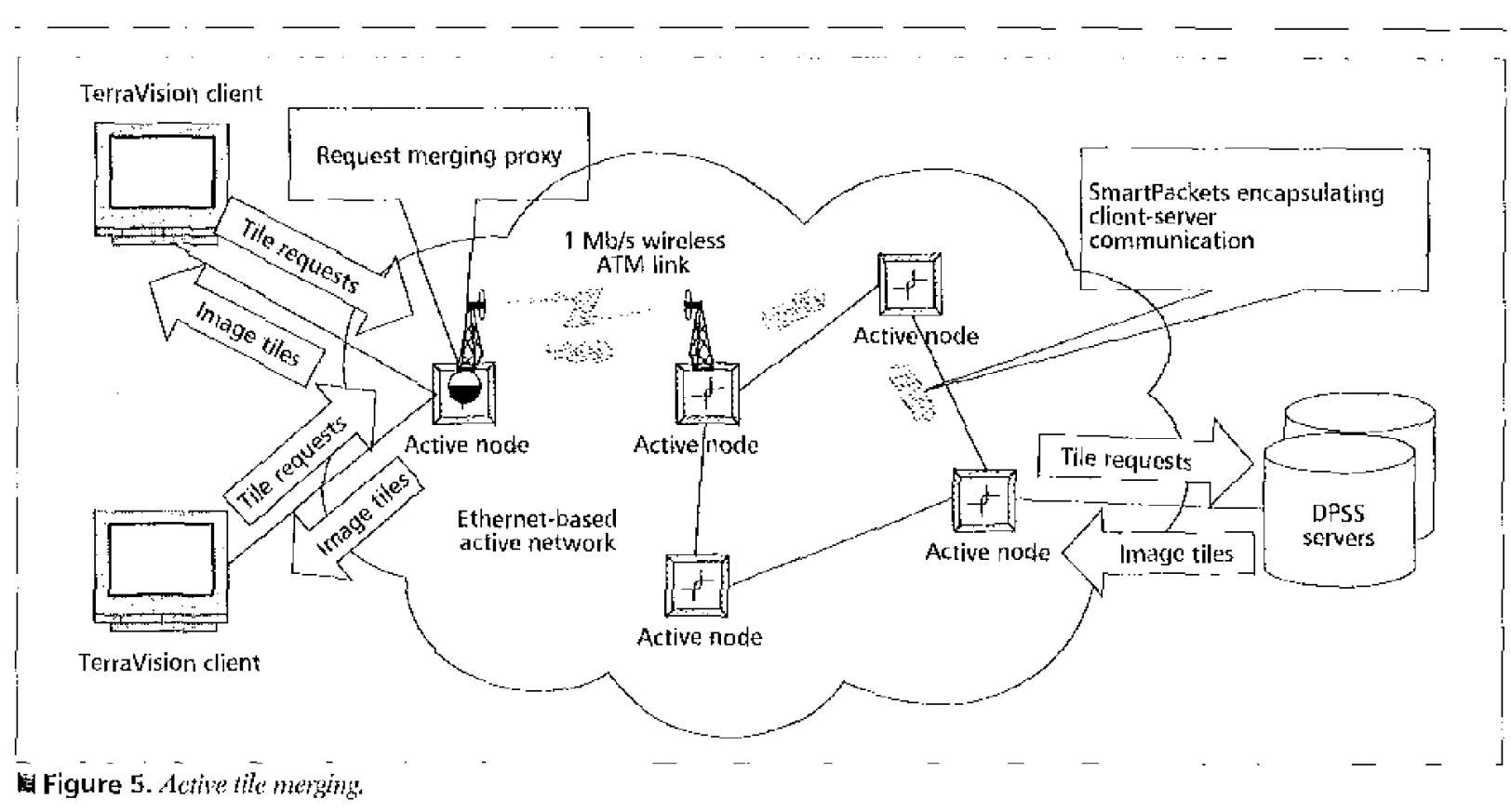

information is stored at the neigluboring nodes and updated periodieally. When a request reachcs an active node, it is rediected to lue nearest proxy based on the information stored at the hode. $\Lambda$ the proxy, if an incoming request has alyeady been made on behalf of another client, the current request is cached. The server's reply is muiticest to all requesting elients.

Most of the packets designed for the filtering application are reused here. The paekets for setting up the cornection, seting up the proxy, and the beacon packets are the same. I'he tile request jacket and tile data packet trameworks requite modification. The lile repuest packet is composed with an interface that identifies and rakes iction on al chplicated request. Sinvilarly, the tile data packet, instead of checking for validity of the tile request delentifier at the proxy, retrieves the number and locition of the slients that mate a request for the curtent tile, and mullicnsts itself to all the clients.

\section{Performance}

Wo conducted expeninonts io measure the performance benefits oblained by implementing the active tile filtering in the network. The prerformance of Tertavision ruming over the traditional 'I'Cl/Il' network stack is compited with Terravision rumilug over an active network inglententing active tile filtering at the wireless gateway. The network, whose topology is shown iil I'jg. 4, includod a $1 \mathrm{Mb} / \mathrm{s}$ wireless link. 'f'lac network consists of five active nodes, a workstation ruming the TernVision application, and another ruming the image server contected by $10 \mathrm{Mb} / \mathrm{s}$ Fithernet. Terravision fotcles 49,332-byte image tiles from the remote server over the wireless link. For the TCP/IP nelwork, a static route ensures that pickets are always forwarded over the wireless link. In the active nelwork, routing was conIrolled so that the route between the client and the seiver included the wireless link. lu active networking, we trade mocessing time at the network aodes for benefits gained by serkeling information rather than data through the network. The beliefits can be in the form of reduced bandwidth demand, better utilization of node resourees such as buffers and queves, and/or ayp plicat jon-specific customizal ion, Porformance. of the network is tradtionally mensured in terms of throughput and delay; but simpiy catculating performance in terms of tiles delivered per second is inappropriate. | wecause Terravision drops tiles that are ontside the uset's frame, at betfer measure is to lind out the number ai liles the application actually displays. Therefore, we deline offective arilization as the fraction of the data tielivered to the application liat is actuthy atilized. Thus, in our experiment, effective ntilization is the ratio of the number of tiles displayed by Terravision to the number of tiles recened by it.

We ran Terea Vision using both TCP/IP and active nelworking to determine qualitatively and quantitatively if active tile liller higg impeoved its performanec. Subjectively, it is observed that when inuning TerralVision over the TCly/P network, navigation was rather jerky ats the flight neared the end ol its path. 'L'his etfeet is not observed when Teravision runs over the active network implementing tile filtering. The most probable reason for llis is that at ligh panning spocils, Tcrat Vision continuously made requests for a large u urnber of tites. TCl'/II', in altempting to deliver all the tequested liles to the application, caused the wireless link to get congested. 'l'his ciused the rendering thead of 'l'erm Vision to wait intermittenty for the congestion at the wircless galeway to be alleviated, which in turu cutsed a large number of tibes 10 be discarded when they did arrive beeause they were not part of the culreat viow, On the oller hand, the tile filtering code in the active network prouclively drops tiles that are not in the current vicw. This prevents congestion at the wireless gatewny and snables the network to reliver the requited tiles 


Powe highor the
The
utilization, the
lower the
bandwidth
wasted by the
network
attempting to
deliver tiles
eventually
dropped by the
application. In
our experiment
this corresponds
to a savings of
over 18 percent
in network
bandwidth over
the wireless
link without
significantly
affecting
performance.

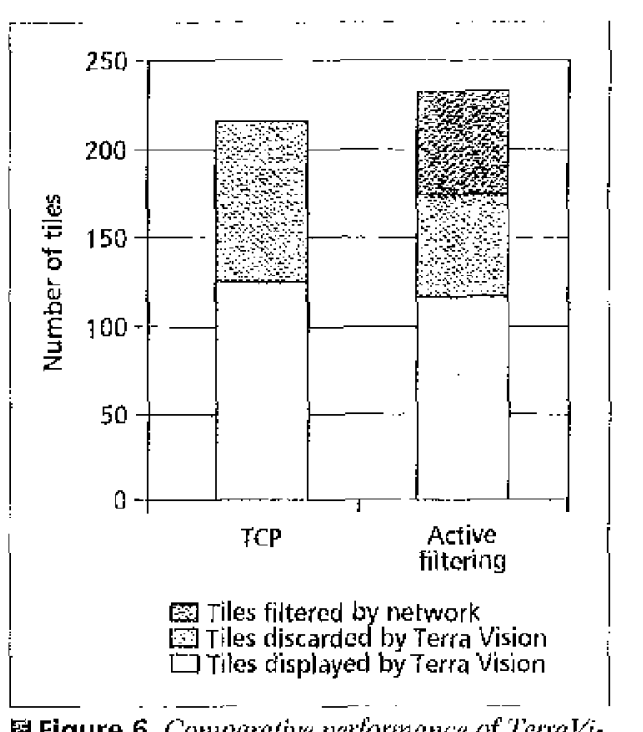

Figure 6. Comparaive performance of Torravision with and without active itle filtering.

to the application in a timely matnnet will higher probability of being displnyed.

This is borne out foom quanlitative analysis of the performance, as shown in Fing. 6. 'The chat compares the number of tiles displayed by Terravision, the number of tiles received but not displayed, and the number of lites filtered by tle network for the two eases. The number of tiles displayed by the application is roughly the same in both cases, which validates observed performatice that the pereejved quality or the inuge is approxitnately the same. We sec that active filtering provides an effective mililization of 0.67 as compared to 0.58 for the TCl$/ L$ Petwotk becalse approximately half of the tardy tites are filtered at the wircless gateway itself, ats shown by the shaded area of the clat. The high er the ntilization, the lower the bandwidth wasted by the nelwork at tempting to deliver tiles eventually dropped by the application. In our experinent, this corresponils to a savings of over 18 pereent in melwork bandwidth over lhe wireless link without significantly affecting performance.

\section{RELATED RESEARCH}

Other active networking prototypes utilize some form of protocol composition ur other. Hoosters are in-kernel protocol modules that alapt to the environment [8]. They are transparently inserted into and deleted fon protoos griphs on an asneeded basis. I lowever, houster protocols cannol be dynamically created and injected into the network. They are preinstalled in the kerrels of the nodes of the network. II is not eleat if booster protocols are developed in a modulat fastion or if their funetionality eatn be extended or overticlden by applications.

ANTS [9] provides a mechanism for protocol composition using the CodeGronp attribute of the $\triangle N T S$ carsule. Code belonging to the same protocol suite (or stack) shates the same Code Grotip attribute. Ptotocol modules are demand-Jaded into the antive node prior to enpsule execution. $A$ wrapper module (which is the main class for the profecol) putis togeduer the protocol modules it? the mance desired by the programmer. Protocol francworks in ANTS are written in Jivil and on theretore potentially support the properties of modularity, introspection, and intercession.

NetSeript [6] is a clatallow programming lau. guage in which computation consists of a collecliom of interconnected proglams, called boxes, that process datia streams tlowing theough libm, Tho limguage supports the constrution of packet processing programs, interoontecling these programs and allocating resources to then. Protocol composition is modular, achicwed by using NelScript construets to define and establisin interconnection between various boxes. $A$ new protocol frinework is created by defining a composite box template that describes the protocol components and their interconnections. The plotocol compunents themselwes are either box tentplates or primitive proerans. The framework is degloyed in the network by clispateling it to indivjalua NetSeript engines at the network nodes. It is obvions that frameworks in Netscript are highly modular. 1t is also shown in [y] that Netscript supports the properties of introspection and intercession.

Switchware [10] provides protocol conposilion using a two-lovel architecture consisting of switchlets and use programs in active packets. Fidel switchlet provides services in the form of melhods manipulating protocols implenented for that switchlet. 'The switchlets services are implemented iu a high-level language and dynanically loaded at the network nodes. Active packets are user packets lhat invoke the services provided by the switchlets. 'The corle in the aclive packets is written in a strongly' yped language callod PLAN that is specifically designed lor ietive networks. PLAN programs are allowed to conpose new protucois from the switclilet services in a modulit fashion. Jut it is not clear if users can exlend (1) replace the functionality of the switehlet services to customize processing arbilarily.

\section{SUMMARY}

In this arlide wo cleswibe the class-hierarchy composition model that cnables tsers to compose and deploy custorn, flexible protocol frameworks llat wer to an application's inmecinte requirements. We outine properties rec]uired o[ enstomizal) ]e frameworks and slow that the class-hicrarchy model siltisties those properties. We int] lemented this rodel in the Magician Loolkit and demo:1stratcd tts tase to design alpplicatiou-specific protecol frameworks that tackle problens in wireless networks. Finally, we repott on studies on the performance of the protocols and show that active network protocols provide benefits to ipplication clata over wircless networks.

\section{REFERENCES}

[1] D. Tonnemhousf and D. Wetherall, "Towards an Active Network Architecture," Comp. Commurn. Rev. vol. 26. ก. 2 , Aि:. 1906.

|2| L. Comer, intermetworking with TCP/P Vol. 2: Design, implementation and internals. Prontice flall, 1998.

[3] R. van Renesse, K. Birman, ane' S. Maffe's, "Horus, A Ficxible Group Communication System." Commur. ACM, vol. 39, no. 4, Apr. 1996, pp. 76. 83 
[4] N, Hutchirison and L. Peterson, "The s-Kernal: An Mrchiterture for Implementing Network Protocols, "ifEE Frars. Sollwaro Eng, vol. 17, no. 1. Jan. 1991, pp, 64-76.

[5] A. Kalkarni at al. "Implementation of a prototype Active Notwork" IEEE Corf. Opon Architecturos and Nowork Frogranming, San Francisco, $C_{A}, A_{2}$ r. 1998.

[G] A. Kulkarni and G. Mirnder" "Active Networking Services for Wired/Nireless Networks," sroc. INFOCOM 99, wol. 3. New York, 1999. pp. 1116 -23.

[7] W. Marcus et al. "Protucol Euosters: Applying Programmability to Notwork Infrastructures," IEEE COHmun. Mag, Oct. 1998.

[3] D. Wietherall. J. Guttag, and [?, Tennenlnouse, "ANJ's: $A$ Toolkit For Building and Dyramically Deploying Not work Protocols s" IEEE Conf. Opon Architectures and Network Prograniming. San Hancisco, CA, Apr 1998.

[9] S. da Silva, D. Florissi, and Y. Yemini, "Composing Active Servicos in WetScript." position parper, DARPA Active Notworks Workhop. Tucsori AZ, Marr. 1999.

[10] 5. Alexander et al. "The Switchware Active Nelwork

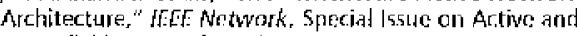
Controllat:je Networks, wol, 12, no. 3, 1999, trp. 2936

\section{BIOGRAPHIES}

MMIT Q. KULKARNI (amit.kulkarni(m) sciontisl at Gonora: Eloctric Research and Dowdopment (GE
CRED). Niskayuna, Wew Yark. [kefore joining Git. CH\&D, he was a rescarcher at the brformation and Telecommunications Techmology Centar (ITTC) int the Uniworsity of Kansas. where he worked on tho [3ARPA Multiblimensional Applications and Gigabit Inter-network Consortium (MAGi|C-II) project. He reccived his Q.E. in flectranis and telecommurications engineering from the Uniwersity of fune, India, in 1989, and his M.5. from the University of Kansas in 1996. He has worked for many years in the industry ats a

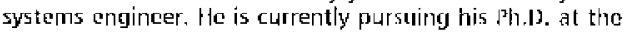
Uniwersity of Kansas.

GAHY J. MIN!HN (B.S.E.F. 1973, Ph. D. 1982, Uniwersity of Kansas) is professor of electrical engineering and computer science at the IJniwersity of Kansas. Ho is a principal investigator on the MAGIC testbed, the Rapidly Deployahte Radio Netwotk, and the Innowatiwo Actiwe Notworking Services project. From June 199t through Decomber 1996 he was on leave at the Defense Advanced Research Projecls Agency (DARPA) Information Technology office and served as a brogram manuger in tlyc area of hichtyperformance networking sustems. While at DARPA he formulated and initiated a new research program in active networking. His resen rch interests are in the aroas of argo scale distributod systoms which encompass high performanef networks, computing systems, and clistributed software systenus.
It is obvious that

frameworks in

Netscript are

highly modular.

It has also been

shown that

Netscript

supports the

properties of

introspection and

intercession.

\section{IEEE Communications Magazine October 2000 Special Issue on Advanced Signaling and Control in Next Generation Networks Call for Papers}

Spurred on by the unprecedented growth of the internat and innovative services that use internet technologies, there has been an ever increasing interest in the ubicjuitous application of packet networks and packet switching tochnologies for provision of voice, data, and different kinds of multimedia services. The time is fast approarhing when a fundamental architectural shift on a large scalc needs to be undertaken to give rise to a truly integrated data-centric multi-scrvico network with a unified control infrastructure. The realization of such an architecture vision has been the dream of notwork stratogists over the last twentyyears. Control and management of such networks, and the services supported by them, present challenges of unprecedented magnitude to the network architects. The radical departure of the technologies associated with this paracligm shift from the traditional circuit-switched technologies is also seriously challenging the way intelligent network services are presently implemented and offered.

New signaling protocols and architectures have emerged for multimedia multiparty confercncing, e.c.. protocols such as ITJ-T II.323. T.120, IETF-SIP, and DAV|CDSM-CC. New architectures have been proposed in For ums and Consortiums such as the Multi-services Switching Forum and TINA-C. There are also new developments taking place in the area of Noxt Generation Networking with the emergance of protocols for gateway control e.g., ITU-T H.GCP and the IF.TF Megaco Protocol that facilitate voica, data and multimedia over packet networks. ETSI TIPHON is also working in this area with particular emphasis on interworking botwcen packet networks and legacy circuit-switched networks.

The goal of this special issue is to focus on the control and manacjement architectures for the new data-centric forms of multiservice communication nelworks, the associated midd leware infrastructurcand protocols that they call for, their scalability and ubiquity, signaling interworking issues, and transformation of circuit-switched networks.

Sperifically, this special issue will include articles on topics including, but not limited to, the following:

- Advanced signaling and control architectures for multi-servire notworks

- Emerging signaling protocols (e.9., IETF/Megaco H.248, ITU-T H.323, IETF SIP) for multi-services over packet (MoP) notworks and how they fit into the transition plans towars the target arclitecture

- Control for of Quality of Service (QoS) in multi-service networks

- Control and management infrastructures for provision of advanced services including real-time and non-real-time multimedia multiparty communicstion senvices, high quality content delivery services, information and data servicos, otc. - Signaling interworking with circuit-switched networks and legacy systems

- Evotution scenarios for migration of today's service architecture of PSTN/AIN, which is optimized for narrowband voice-centric circuit-switched services, to the unified target control architecture optimized for data-centric multi-service notworks.

Original articles, not previously published, are solicited. Prospective anthors are invited to submit five copplos of their paper to ono of the Guest Editors by April 15, 2000. Authors will be notified by tune 15, 2000. Rovised proposals are due to the Guest Editors by July 15,2000. Given the scope and importance of the subject, we anticipate that selected articles will be pulslished in a twopart series. The publication date of the first special issule is October 2000.

Guest Editors:

Dr. A. R. Modarressi

BellSouth Science and Technology

675 Wost Ponchtroo St., NE

Room 40^54

Atlanta, Georgia 30375

modar@bridge.bellsouth.com
Dr. S. Mohan

Talcordia Technologies, Inc.

$\operatorname{MCC} 1 \mathrm{~A} 216 \mathrm{~B}$

445 South Street

Morristown, NJ 07960, USA

smohan@etcordia.com 